\title{
Thiazolidinediones: the Forgotten Diabetes Medications
}

\author{
Harold E. Lebovitz ${ }^{1}$ \\ Published online: 27 November 2019 \\ (C) The Author(s) 2019
}

\begin{abstract}
Purpose of Review Thiazolidinediones (TZDs) are the only pharmacologic agents that specifically treat insulin resistance. The beneficial effects of TZDs on the cardiovascular risk factors associated with insulin resistance have been well documented. TZD use has been limited because of concern about safety issues and side effects.

Recent Findings Recent studies indicate that cardiovascular toxicity with rosiglitazone and increase in bladder cancer with pioglitazone are no longer significant issues. There are new data which show that pioglitazone treatment reduces myocardial infarctions and ischemic strokes. New data concerning TZD-mediated edema, congestive heart failure, and bone fractures improves the clinician's ability to select patients that will have minimal significant side effects.

Summary Thiazolidinediones are now generic and less costly than pharmaceutical company-promoted therapies. Better understanding of the side effects coupled with clear benefits on the components of the insulin resistance syndrome should promote TZD use in treating patients with type 2 diabetes.
\end{abstract}

Keywords Type 2 diabetes $\cdot$ PPAR $\gamma$ agonists $\cdot$ Insulin resistance $\cdot$ CV outcomes $\cdot$ Heart failure $\cdot$ Bone fractures

\section{Introduction}

For years there was an intense debate as to whether the primary defect in type 2 diabetes (T2D) was insulin resistance or insulin secretory deficiency. This conflict has been resolved in that hyperglycemia only occurs when insulin secretion is insufficient to overcome barriers to insulin action [1•]. Thus, when insulin action is normal, hyperglycemia occurs when absolute insulin secretion is deficient. In contrast, when insulin action is impaired (insulin resistance), hyperglycemia occurs when insulin secretion is inadequate to overcome the insulin resistance. While a few investigators suggest that hyperinsulinemia itself may be a primary cause of insulin resistance, the overwhelming data indicate that insulin resistance is a primary defect due to abnormalities in the distribution of adipose tissue products in hepatic and extrahepatic

This article is part of the Topical Collection on Pharmacologic Treatment of Type 2 Diabetes

Harold E. Lebovitz

hlebovitz1@hotmail.com

1 SUNY Downstate Medical Center, 450 Clarkson Avenue, Box 1205, Brooklyn, NY 11203, USA tissues $[2 \bullet \bullet, 3 \bullet \bullet, 4]$. These ectopic increases in lipids define the metabolic syndrome. The metabolic syndrome results in increases in atherosclerotic diseases, hepatic steatosis and steato-hepatitis, and hypertension $[5,6 \bullet \cdot]$. Insulin resistance increases the prevalence of T2D sixfold as marginal insulin secretion becomes inadequate insulin secretion $[7,8]$.

Patients with T2D may have hyperglycemia and no metabolic syndrome (up to $15 \%$ of patients with T2D) or hyperglycemia with the metabolic syndrome (85\% of patients with T2D) $[9,10 \bullet \cdot$. Data from NHANES III participants 50 years or older showed that patients with T2D and no metabolic syndrome had a prevalence of coronary heart disease of $7.5 \%$ which did not differ from a non-diabetic population with no metabolic syndrome (prevalence 8.7\%) [10••]. Patients with no diabetes and the metabolic syndrome had a $13.9 \%$ prevalence of coronary heart disease and those with diabetes and the metabolic syndrome had a $19.2 \%$ prevalence of coronary heart disease $\left[10^{\bullet}\right]$. These and other data suggest that the metabolic syndrome is the driving factor in the development of cardiovascular disease and that hyperglycemia is a factor that exaggerates cardiovascular disease in the metabolic syndrome setting.

This formulation of insulin-resistant $\mathrm{T} 2 \mathrm{D}$ as two interacting pathophysiologic entities (Fig. 1) suggests that appropriate 
Fig. 1 Insulin-resistant type 2 diabetes is the co-existence of two separate metabolic abnormalities: a primary beta-cell disease: diabetes mellitus and a lipid distribution abnormality which creates insulin resistance, the metabolic syndrome, and increased cardiovascular disease. These abnormalities can be separate or co-exist. These abnormalities can interact in susceptible populations leading to an increase in the prevalence of diabetes and an increase in atherosclerotic disease

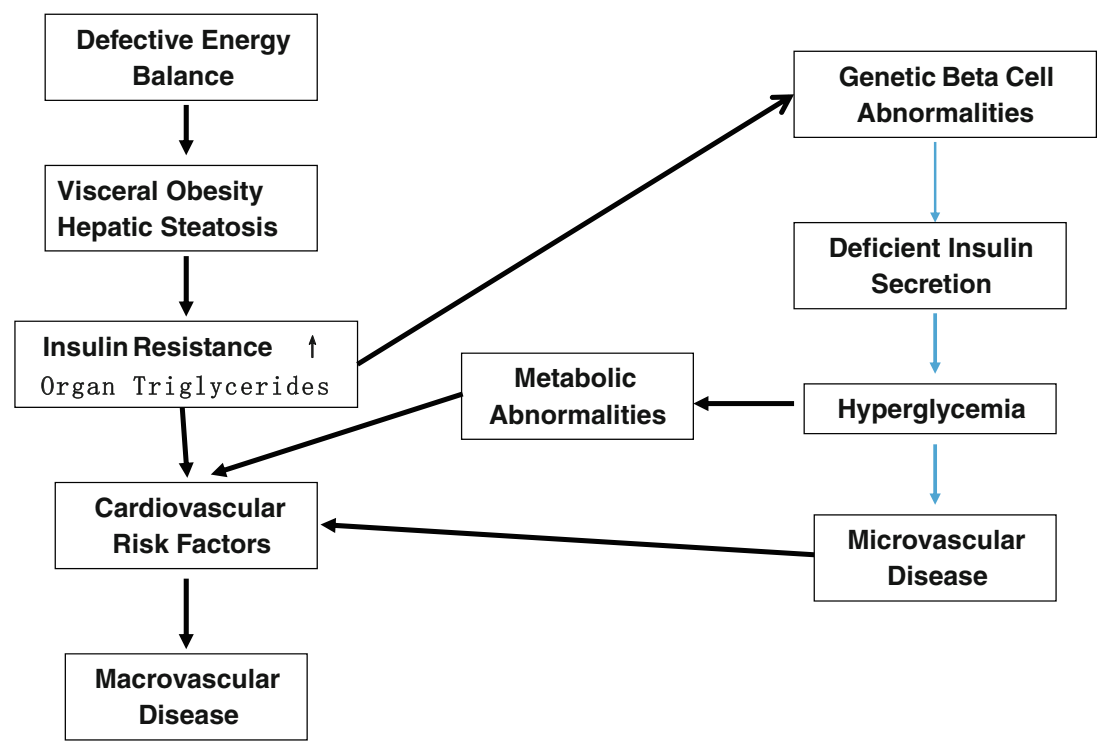

treatment should target both the insulin resistance and the inadequate insulin secretion. Therapeutic agents such as insulin, sulfonylureas, and meglitinides target primarily insulin availability [11]. Glucagon-like peptide 1 (GLP-1) receptor agonists and dipeptidyl dipeptidase 4 (DDP-4) inhibitors increase insulin secretion and decrease hyperglucagonemia, thereby lowering hyperglycemia [12-14]. GLP-1 receptor agonists have modest effects in decreasing body weight and lowering systolic blood pressure [12, 13]. The sodiumglucose transport 2 (SGLT-2) inhibitors lower blood glucose through an increase in renal excretion of glucose with a secondary benefit of decreasing glucose toxicity [15]. They increase hepatic glucose production, glucagon secretion, ketogenesis, and lipid oxidation [15, 16]. A significant side effect of their treatment is a modest weight loss, a decrease in blood pressure, and a modest reduction in insulin resistance $[15,16]$. Weight loss itself decreases hepatic triglycerides, peripheral and visceral adipose tissue mass, and plasma triglycerides [17•]. GLP-1 receptor agonists and SGLT-2 inhibitors secondarily decrease insulin resistance in patients in proportion to their effect in promoting weight loss. Thiazolidinediones (TZDs) decrease insulin resistance directly through activation of PPAR $\gamma$ receptors which facilitate differentiation of mesenchymal stem cells into adipocytes, promote lipogenesis in peripheral adipocytes, decrease hepatic and peripheral triglycerides, decrease activity of visceral adipocytes, and increase adiponectin [18••, 19, 20]. These primary effects of TZDs markedly ameliorate insulin resistance and the metabolic syndrome and decrease insulin requirements [18••, 19, 20]. While metformin decreases hepatic insulin resistance, it has little or no primary effect on peripheral insulin resistance [21, 22]. Metformin's effects on hepatic insulin resistance are likely to be due to its inhibition of mitochondrial complex 1 resulting in defective cyclic AMP signaling [22].

\section{Clinical Benefits of Thiazolidinediones}

The metabolic consequences of insulin resistance are an increase in the incidence of T2D and an increase in cardiovascular diseases $[7,8]$. Insulin resistance decreases pancreatic beta-cell function by causing compensatory hyperinsulinemia, beta-cell lipotoxicity, and increasing islet inflammation [22, 23]. These factors result in increased betacell apoptosis and progressive decreases in insulin secretory capacity. Insulin resistance is associated with increases in multiple cardiovascular risk factors $[2 \bullet \bullet, 3 \bullet \bullet, 4,5,6 \bullet]$. Insulin resistance creates a dyslipidemia consisting of increases in plasma-free fatty acids and triglycerides, decreases in HDL-cholesterol, decreases in adiponectin, and increases

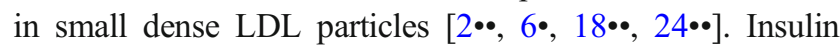
resistance is a major cause of hepatic steatosis and steatohepatitis $(\mathrm{NASH})[24 \bullet \bullet]$. Insulin resistance creates a procoagulant state with increases in fibrinogen and plasminogen activator inhibitor-1 (PAI-1) [5, 6•]. Insulin resistance increases inflammation and is associated with an increase in C-reactive protein (CRP), IL-6, and TNF $\alpha$ [25, 26]. Insulin resistance is associated with endothelial dysfunction as measured by decreased vasodilatation, increase in adhesion molecules, and an increase in cellular proliferation [5, 27]. An increase in hepatic and visceral fat leads to ectopic deposits of lipids in tissues such as skeletal muscle, myocardial muscle, and endothelial cells, causing a decrease response to

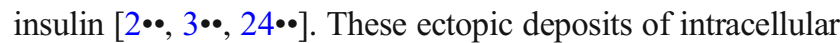
lipids within muscle and endothelial cells increase serine and threonine phosphorylation and decrease tyrosine phosphorylation of insulin receptor substrates and phospho-inositol 3kinase, thereby decreasing intracellular insulin signaling $[2 \bullet \bullet, 24 \bullet \cdot$. An increase in beta-cell lipids decreases its insulin secretory function [23, 28]. 
Significant weight loss in obese insulin-resistant individuals will secondarily reduce insulin resistance and the components of the insulin resistance syndrome [17, 29]. TZDs through their activation of PPAR $\gamma$ have primary effects on adipose tissue and decrease insulin resistance by reducing hepatic triglycerides, decreasing visceral fat mass and activity and increasing subcutaneous fat mass $[2 \bullet \bullet, 18 \bullet \bullet, 19,20]$. This primary action of TZDs in reducing insulin resistance accounts for their beneficial effects in ameliorating the detrimental effects of insulin resistance. Table 1 describes the beneficial effects of TZDs in the treatment of patients with T2D $[2 \bullet \bullet, 18 \bullet \bullet, 20,30$, 33]. TZDs decrease both fasting and postprandial hyperglycemia by decreasing insulin resistance and allowing endogenous insulin to be more effective. Where measured, TZDs have a more durable effect in reducing hyperglycemia than other antihyperglycemic agents [34]. The multiple effects in decreasing dyslipidemia, endothelial dysfunction, inflammation, and the procoagulant state and increasing adiponectin are thought to provide some potential cardiovascular benefits. The effects of TZDs in reducing hepatic steatosis suggest potential therapeutic benefits in reducing NASH. The reduction in insulin resistance in patients with prediabetes decreases their rate of progression to $\mathrm{T} 2 \mathrm{D}$, presumably by preserving beta-cell function [31•, 32•]. Between 2000 and 2008, pioglitazone and rosiglitazone were among the most widely prescribed antidiabetic medications. However, there were increasing concerns about TZDs' side effects: increased fluid retention; increased incidence of heart failure; weight gain; and increased peripheral fractures $[35 \cdot 36 \bullet \cdot$. Regulatory concerns about cardiovascular safety issues with rosiglitazone and increases in bladder cancer with pioglitazone markedly reduced the availability of these drugs [37-39]. Since the regulatory issues appear to have been greatly exaggerated and TZDs are the only agents that primarily target insulin resistance, the use of these relatively inexpensive drugs justifies a re-evaluation of their clinical use.

Table 1 Beneficial effects of thiazolidinediones in the treatment of patients with insulin resistance $[3 \bullet \bullet, 18 \bullet \cdot, 20,25-27,30,31 \bullet, 32 \cdot]$

1. Improves insulin sensitivity in insulin-resistant individuals from 25 to $68 \%$ depending on the study and technique used (euglycemic-hyperinsulinemic clamp, Bergman minimal model, Homeostasis Model Assessment of Insulin Resistance (HOMA-IR))

2. Effects on adipose tissue

a. Increase subcutaneous adipose tissue mass approximately $3.5 \%$

b. Little no effect on visceral adipose tissue mass

3. Effects on dyslipidemia

a. Decreases plasma-free fatty acids 25 to $35 \%$

b. Increase in plasma HDL cholesterol 10 to $20 \%$

c. Plasma triglycerides reduced particularly if baseline value $>200 \mathrm{mg} / \mathrm{dL}$

d. Small dense LDL particles are converted to large buoyant LDL particles

e. Increases adiponectin

4. Decrease in hepatic triglyceride concentration (hepatic steatosis)

5. Effects on endothelium

a. Vasodilatation is increased

b. Systolic and diastolic blood pressure decreased 4 to $5 \mathrm{mmHg}$

c. Production of adhesion molecules (VCAM 1, ICAM 1) are decreased

d. Vascular smooth muscle cell proliferation is inhibited

e. Neointimal tissue proliferation after coronary stent implantation in type 2 diabetes is reduced $50-70 \%$

6. Effects on inflammation

a. Reduces mean plasma C-reactive protein (CRP) by $25-30 \%$

b. WBC counts and metalloproteinase are reduced

7. Effects on procoagulant state

a. Reduces plasminogen activator inhibitor 1 (PAI-1) approximately $25 \%$

b. Reduces plasma fibrinogen

8. Effect on glycemic control

a. Thiazolidinedione reduction in glycated hemoglobin $(\mathrm{HbAlc})$ results from decreases in both fasting and postprandial hyperglycemia

b. The magnitude of decrease in HbAlc is a function of the magnitude of improvement in resistance and the extent of residual insulin secretion

c. In large clinical trial such as PROactive, HbA1c was reduced $-0.8 \%$ from baseline $7.8 \%$ with $53 \%$ reduction in insulin dose

d. The ADOPT study data showed that rosiglitazone had a significantly greater durability in controlling glycemia after 5 years of treatment of patients with type 2 diabetes than either metformin or glyburide

9. Effect in preserving beta-cell function

a. In separate studies, rosiglitazone (DREAM) and pioglitazone (ACT NOW) decreased the progression of prediabetes to diabetes by $60 \%$ and $72 \%$, respectively, after a median treatment of 3.0 and 2.4 years

b. Decrease in progression from prediabetes to diabetes in both trials was most closely associated with preservation of beta-cell insulin secretory function 


\section{Effects of Thiazolidinediones on Cardiovascular Outcomes}

Since TZD treatment improves insulin resistance and decreases many cardiovascular risk factors, it had been proposed that treatment of patients at high risk for cardiovascular events with TZDs might have a beneficial effect in reducing long-term cardiovascular events. Clinical studies have examined the effects of pioglitazone and rosiglitazone on cardiovascular outcomes, and several meta-analyses and large database analyses have compared their relative cardiovascular outcomes.

\section{Pioglitazone}

The PROactive (PROspective pioglitAzone Clinical Trial In Macrovascular Events) trial randomized 5238 patients with T2D and evidence of macrovascular disease between May 2001 and April 2002 into a controlled, double-blind, cardiovascular outcome trial with pioglitazone titrated 15 to $45 \mathrm{mg} /$ day or placebo [40••]. The primary endpoint was a composite of all-cause mortality, non-fatal myocardial infarction (including silent myocardial infarction), stroke, acute coronary syndrome, endovascular or surgical intervention in coronary or leg arteries, and amputation above the knee. After an average duration of 34.5 months, pioglitazone failed to meet the primary endpoint of a reduction in at least one those composite hard or soft cardiovascular endpoints (hazard ratio (HR) $0.90, p=0.095)$. There was a significant reduction in the main secondary endpoint of all-cause mortality, non-fatal myocardial infarction (excluding silent myocardial infarctions), and stroke $(\mathrm{HR}=0.84, p=0.027)$ [40••]. Pioglitazone caused a significant increase in hospitalization for heart failure (149 vs. 108 placebo-treated patients, $p=0.007)$; however, mortality rates for heart failure did not differ from the placebo group. The results of the PROactive study were extensively debated because of the inclusion of so many diverse components in the primary endpoint, the exclusion of silent myocardial infarctions in some analyses, and differences in numbers of events in the primary and secondary analyses. Some reviewers claimed that the results showed a significant decrease in cardiovascular outcomes, and others argued that the design and statistical analyses were flawed, and the conclusions reached by the investigators were invalid. One finding that everybody agreed upon was that pioglitazone increased the incidence of hospitalizations but not the mortality for congestive heart failure. Weight gain (pioglitazone $3.6 \mathrm{~kg}$ vs. placebo $-0.4 \mathrm{~kg}$ ) and peripheral edema (pioglitazone 562 patients vs. placebo 341 patients) were increased in the pioglitazone-treated population as was expected from its known side effects [40••].

While the data do not prove conclusively that pioglitazone reduces cardiovascular events, the data are consistent with a benefit. The weakness in the PROactive study lies in the endpoint assumptions made. It should be noted that this was the first major cardiovascular outcome study evaluating a single antidiabetic treatment.

The results of two recent, large, well-designed trials have provided new meaningful data on the effects of pioglitazone on cardiovascular outcomes. The Insulin Resistance Intervention after Stroke (IRIS) trial, which was a multicenter, double-blind trial that investigated the effect of pioglitazone on future cardiovascular events in patients who had insulin resistance and had had a recent ischemic stroke or a transient ischemic attack [41••]. Three thousand eight hundred seventysix participants without diabetes were treated with pioglitazone $45 \mathrm{mg}$ or a placebo. Insulin resistance was defined as a measured Homeostasis Model Assessment, HOMA-IR > 3.0. The primary outcome was fatal or non-fatal stroke or myocardial infarction. By 4.8 years, 175 of 1939 (9.0\%) patients treated with pioglitazone and 228 of 1937 (11.8\%) placebotreated patients had a primary event. The HR for pioglitazone treatment was 0.76 (95\% CI 0.62-0.93). Diabetes developed in 73 participants (3.8\%) receiving pioglitazone and 149 participants $(7.7 \%)$ receiving placebo, $\mathrm{HR}=0.48, p=0.001$. No significant difference occurred in all-cause mortality (HR = 0.93). Pioglitazone therapy was associated with an increase in weight gain $>4.5 \mathrm{~kg}(52.2 \%$ vs. $33.7 \%), p<0.001$; edema $35.6 \%$ vs. $24.9 \%, p<0.001$; and bone fractures requiring surgery or hospitalization $5.1 \%$ vs. $3.2 \%, p=0.003[41 \bullet \cdot]$.

The TOSCA-IT study was a large multicenter trial which evaluated the cardiovascular outcomes of the long-term effect of adding pioglitazone vs. a sulfonylurea to patients with T2D inadequately controlled on monotherapy with metformin [42]. From September 18, 2008, to January 15, 2014, 3028 patients inadequately controlled with metformin were randomized to add either pioglitazone (15 to $45 \mathrm{mg}$ ) or a sulfonylurea (5$15 \mathrm{mg}$ glibenclamide, 2-6 mg glimepiride, or 30-120 mg gliclazide). The study was unblinded, but adjudicators were blinded. Primary outcome was a composite of all-cause mortality, non-fatal myocardial infarction, non-fatal stroke, or urgent coronary revascularization. Of the 1493 participants randomized to sulfonylureas, 24 were taking glibenclamide, 723 glimepiride, and 745 gliclazide. At baseline, 335 (11\%) had had a previous cardiovascular event. The study was stopped at a mean follow-up of 57.3 months because of the lack of any difference in the primary endpoint (pioglitazone 105 participants, 1.5 events/100 person-years; sulfonylureas 108 participants, 1.5 events $/ 100$ person-years, $\mathrm{HR}=0.96, p=0.79$ ). Hypoglycemia occurred in $148(10 \%)$ participants in the pioglitazone group and in 508 (34\%) participants in the sulfonylurea group. Weight gain $<2 \mathrm{~kg}$ on average occurred in both groups. Rates of heart failure, bladder cancer, and fractures were not significantly different between groups [42]. It is of interest that the results of TOSCA-IT and RECORD are very similar, and raise the possibility that the results of cardiovascular outcome studies may differ depending on whether the 
comparator is placebo or an active antihyperglycemic agent $[42,43 \cdot]$.

The effects of pioglitazone in patients with previous strokes or transient ischemic attacks has been further investigated by subanalysis of previous clinical trials or meta-analyses of several studies. In the PROACTIVE study, a subanalysis was done of the 486 pioglitazone-treated patients and the 498 placebo-treated patients that had had a previous stroke [44]. Pioglitazone reduced fatal and non-fatal stroke 5.6\% vs. placebo $10.2 \%, p=0.0085$; HR 0.53 , and the composite cardiovascular endpoint of cardiovascular death, non-fatal myocardial infarction, and non-fatal stroke $13.0 \%$ vs. placebo $17.7 \%$, $p=0.0467 ; \mathrm{HR}=0.72$ [44]. In a secondary analysis of the IRIS trial, patients were stratified above and below the median for risk for stroke and myocardial infarction at baseline [45]. The efficacy of pioglitazone for preventing stroke or myocardial infarction and for safety (death, heart failure, weight gain, and fracture) was determined for each stratum. In the low-risk stratum, the risk for pioglitazone-treated participants was $6.0 \%$ and for placebo-treated participants $7.9 \%$. The absolute difference was $-1.9 \%$ (95\% CI $=-4.4$ to $0.6 \%)$. Among higher risk patients, pioglitazone $14.7 \%$ placebo $19.6 \%$ with an absolute difference of $-4.9 \%(95 \% \mathrm{CI}=-8.6$ to 1.2$), \mathrm{HR}=$ 0.77 vs. 0.75 [45]. Pioglitazone increased weight more in higher risk patients. Fracture risk was greatest in the highrisk group [45].

Meta-analysis of 3 studies with 4980 participants showed that pioglitazone treatment in participants with insulin resistance, prediabetes, and diabetes had a lower risk of recurrent stroke, $\mathrm{HR}=0.68, p=0.01$, and of future major vascular events, $\mathrm{HR}=0.75, p=0.0001$. There was no evidence of an effect on all-cause mortality, and heart failure [46].

Many small trials have investigated the effects of pioglitazone on cardiovascular endpoints or their surrogates. These studies by themselves are not powered enough or of long enough duration to provide significant information about clinical cardiovascular outcomes. They have been included in systemic reviews and meta-analyses. However, the analyses in these reviews and meta-analyses are dominated by the data from the 9114 subjects from the PROactive and IRIS studies and therefore provide little additional information. An exception is the PERISCOPE study which measured coronary atheroma volume by intravascular ultrasonography in a doubleblind, randomized trial of pioglitazone 15 to $45 \mathrm{mg}$ vs. glimepiride 1 to $4 \mathrm{mg}$ in participants with type 2 diabetes [47]. After 18 months, percent atheroma volume decreased $0.16 \%$ in the pioglitazone-treated participants and increased $0.73 \%$ in the glimepiride-treated participants $(p=0.002)$ [47]. These data along with several other studies showing that pioglitazone decreased coronary restenosis after a stent placement indicate that pioglitazone decreases the rate of coronary atherosclerosis.

\section{Rosiglitazone}

Several early clinical trials involving rosiglitazone treatment of participants with prediabetes or T2D showed an imbalance of more cardiovascular events in the rosiglitazone arm compared with placebo. In 2000, the European Regulatory Agency requested a post-marketing study of long-term cardiovascular morbidity and mortality in participants with T2D treated with rosiglitazone (RECORD study). In 2007, Nissen and Wolski published a meta-analysis of 42 clinical trials which showed that rosiglitazone increased myocardial infarction $($ odds ratio $(\mathrm{OR})=1.43,95 \% \mathrm{CI}=1.03-1.98, p=0.03$ ) and death from cardiovascular causes $(\mathrm{OR}=1.64,95 \% \mathrm{CI}=$ 0.98-2.74, $p=0.060$ ) compared with the control group [37]. Another meta-analysis published the same year involving 14,291 participants from 4 clinical trials reported that rosiglitazone increased myocardial infarctions $(\mathrm{RR}=1.42$, $95 \% \mathrm{CI}=1.06-1.93, p=0.02)$ and heart failure $(\mathrm{RR}=2.09$, $95 \% \mathrm{CI}=1.52-2.88, p<0.001)$ compared with the control groups [38]. No increased risk of cardiovascular mortality was found $(\mathrm{RR}=0.90, p=0.53$ ) [38].These publications and the results of several other meta-analyses and database analyses served to raise significant safety concerns about rosiglitazone, and the US FDA assembled several advisory board meetings to review rosiglitazone safety data and make recommendations. An advisory board in July 2007 voted 20:3 that the evidence indicated that rosiglitazone increased the risk of cardiovascular events and 22:1 that the overall risk benefit ratio justified its continuing marketing [48, 49]. Despite the publication of RECORD which showed no differences in cardiovascular events or death from rosiglitazone treatment compared with metformin or sulfonylurea treatments, the European Marketing Authority recommended removal of rosiglitazone from the European market on September 23, $2010[50,51 \bullet, 52 \bullet]$.

A retrospective analysis comparing rosiglitazone to pioglitazone in 2010 concluded that rosiglitazone was associated with an increased risk of composite cardiovascular events (acute myocardial infarction, stroke, heart failure, or death $)(\mathrm{HR}=1.18,95 \% \mathrm{CI}=1.12-1.23)$ compared with pioglitazone in patients 65 years or older [53]. In 2011, under continuing pressure, the US FDA placed very stringent requirements for the use of rosiglitazone in the USA which virtually abolished its use (10,000 US patients used it in 2012) [54]. In June 2013, another FDA panel reviewed all available data including re-adjudicated RECORD trial data and found no evidence of increased cardiovascular risk with Avandia (rosiglitazone) and voted to remove the restrictions on Avandia marketing in the USA [55]. The FDA removed the restrictions in November 2013, but rosiglitazone use had virtually stopped.

RECORD was an exception to most cardiovascular outcome studies in that it was a comparative study of 
rosiglitazone vs. an active treatment. The design of PROACTIVE and the GLP-1 receptor agonists and SGLT-2 inhibitors cardiovascular outcome studies compared the pharmacologic drug to a placebo control. The FDA and GlaxoSmithKline agreed that a large randomized, controlled trial of rosiglitazone compared with pioglitazone and placebo on major cardiovascular outcomes (MACE) was necessary to definitively determine the effects of rosiglitazone on cardiovascular outcomes. The TZD study design was to randomize 16,000 participants with T2D to rosiglitazone, pioglitazone, or placebo and follow them for non-fatal myocardial infarction, non-fatal stroke, or death due to cardiovascular causes for approximately 5.5 years [56]. The trial was stopped prematurely on July 21, 2010, after 162 days because of the regulatory issues related to rosiglitazone from FDA Advisory Committee recommendations and a US Senate report in May 2010 [56].

Secondary analyses of the BARI-2D trial which evaluated outcomes of bypass angioplasty revascularization in which patients were treated with rosiglitazone for a mean of 4.5 years reported that neither on treatment nor propensity-matched analysis supported an association of rosiglitazone treatment with an increase in major ischemic cardiovascular events [57]. A secondary analysis of the Veterans Affairs Diabetes Trial reported that rosiglitazone use was associated with decreased risk of the primary cardiovascular composite outcome and cardiovascular death [58]. Rosiglitazone did not lead to a higher risk of myocardial infarction.

Several studies were designed to evaluate the effects of rosiglitazone on specific aspects of coronary artery disease. In an 18-month study of 672 subjects with T2D and at least 1 atherosclerotic plaque with luminal narrowing in a coronary artery who were randomized to rosiglitazone or glipizide, there was no significant difference in percent atheroma volume (95\% CI $=-1.46-0.17 p=0.12)$ [59]. In a controlled, randomized study of 83 participants with diabetes who had percutaneous coronary artery stent placement, rosiglitazone significantly reduced restenosis at 6 months compared with the control treatment (17.6 vs. $38.2 \%, p=0.030$ ) [60]. Baseline and follow-up glucose and lipid levels between the two groups were not different but rosiglitazone treatment reduced high-sensitivity CRP concentration. The effects of rosiglitazone vs. placebo with standard treatment on echocardiographic function and cardiac status of 224 participants with T2D with left ventricular ejection fraction (LVEF) $\leq 45 \%$ and New York Heart Association (NYHA) functional class I or II heart failure were evaluated in a randomized study [61]. LVEF was similar between the groups at baseline and after 52 weeks of treatment. Rosiglitazone treatment resulted in better glycemic control (HbA1c-0.65\%), worsening edema and increased congestive heart failure medications.

\section{Thiazolidinediones and Weight Gain}

Weight gain has been associated with both rosiglitazone and pioglitazone treatments $[35 \cdot, 40 \bullet$. The weight gain appears to be dose-related ( 1 or $1.5 \mathrm{~kg}$ at low doses) and is greater during combination therapy with insulin secretagogues ( 2 to $3 \mathrm{~kg}$ ) and remarkably so when TZDs are combined with insulin therapy ( 3.5 to $6 \mathrm{~kg}$ ). The weight gain is attributable to several factors: increase in subcutaneous fat mass with either no change or a small decrease in visceral fat mass, fluid retention, and positive calorie balance because of improved glycemic control. Though the increase in subcutaneous fat mass is distressing to patients with T2D who are trying to lose weight, the TZD-mediated changes in fat mass distribution is related to the improvement in insulin resistance and glycemic control.

\section{Thiazolidinediones: Fluid Retention and Edema}

During the pre-marketing clinical trials of pioglitazone and rosiglitazone, it was noted that an increase in peripheral edema and the development of congestive heart failure occurred in a few patients. Patients with NYHA functional class III and IV heart failure had been excluded from the clinical studies. Shortly after rosiglitazone and pioglitazone were marketed for clinical use, data appeared which indicated that edema and congestive heart failure were significant complications of TZD treatment of patients with diabetes mellitus. The magnitude of the problem was sufficiently important that the American Diabetes Association and the American Heart Association held a Consensus Conference to discuss and publish a Consensus Statement on "Thiazolidinedione Use, Fluid Retention, and Congestive Heart Failure" [35•].

The consensus derived from meta-analyses and large databases was that monotherapy with either pioglitazone or rosiglitazone is associated with a 3 to $5 \%$ incidence of peripheral edema which increases to 7.5 to $8 \%$ when they are combined with other antidiabetic agents such as sulfonylureas [35•]. When TZDs are combined with insulin therapy, the incidence of peripheral edema is approximately 15 to $16 \%$ as compared with insulin alone which is 5 to $7 \%$ [35•].

Initially, it was thought that activation of PPAR $\gamma$ receptors in the renal collecting duct epithelium's sodium channel $(\mathrm{ENaC})$ was responsible for TZD-related peripheral edema, hemodilution, and even macular edema [62]. It now appears that sodium transporters in the proximal tubule including NHE3 also contribute to sodium reabsorption [63]. Increased vascular permeability through increased vascular endothelial growth factor secretion and decreased systemic vascular resistance are non-kidney factors that contribute to the edema [63].

Table 2 presents data on TZD-mediated edema from randomized, controlled clinical trials and a large French 


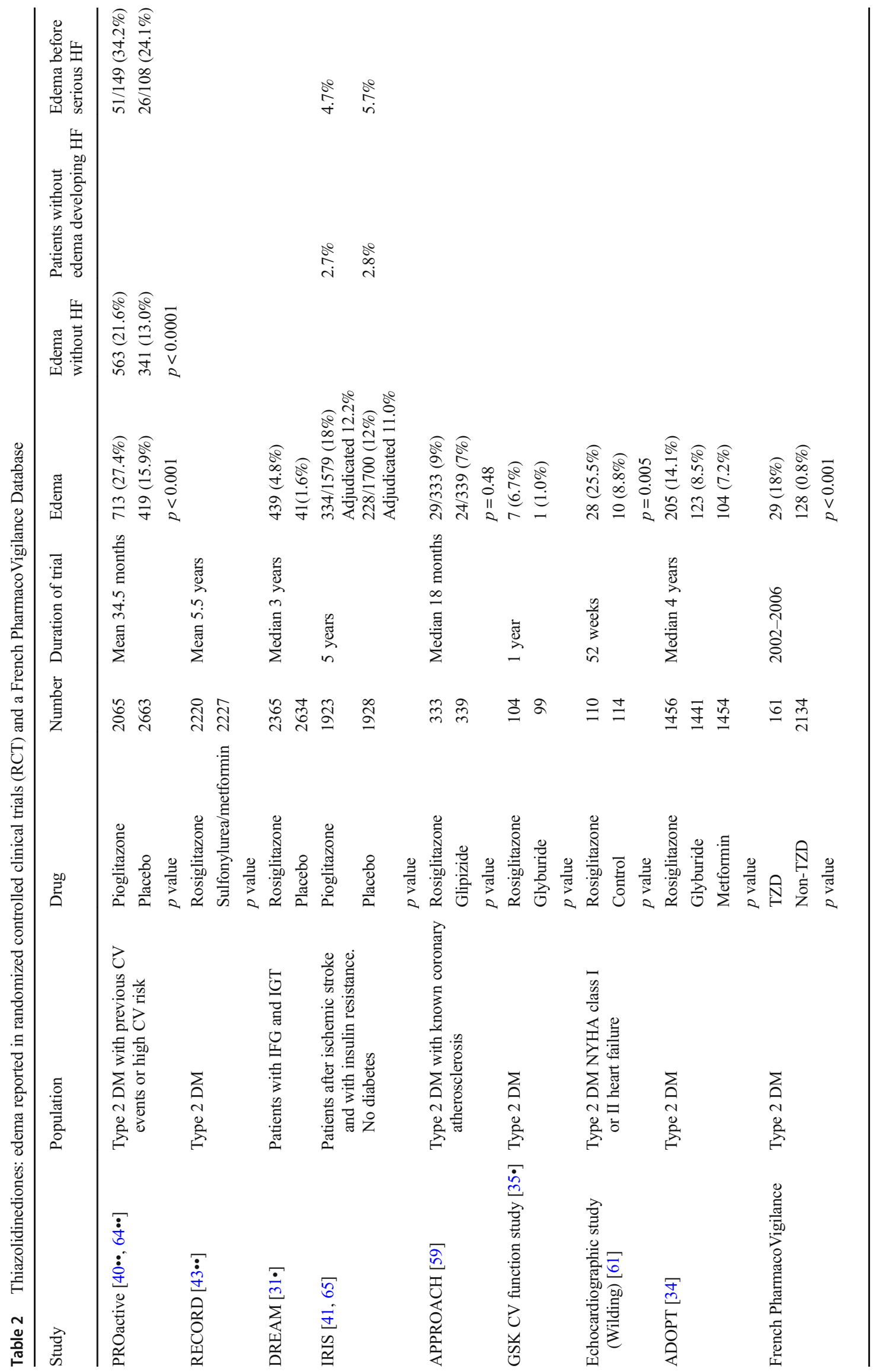


Pharmacovigilance data base. The incidence of TZD-induced edema depends on drug dose, the stage of glucose intolerance, and the magnitude of the underlying cardiovascular disease. The lowest incidence is in prediabetes (DREAM study), with intermediate incidence in T2D (ADOPT and French PharmacoVigilance studies), and the highest in those with advanced cardiovascular disease (PROactive and IRIS studies) $[31 \bullet, 34,64 \bullet \cdot, 65 \bullet \bullet, 66 \bullet]$. The extent to which TZD use exacerbates fluid retention in congestive heart failure is unclear [67].

\section{Thiazolidinediones and Heart Failure}

Heart failure is the most significant side effect of treatment with TZDs. Many meta-analyses and database analyses have been published and have concluded that both pioglitazone and rosiglitazone increase the incidence of heart failure in patients with T2D [68-71]. However, they cannot provide data on the severity, progression, and clinical outcome of the patients. Table 3 presents the available data on TZD treatment and the development of heart failure in randomized, controlled clinical trials. Data are available in patients with insulin-resistant and no diabetes, prediabetes, ordinary T2D, and T2D with previous cardiovascular events. Patients with prediabetes treated with TZDs have a very low incidence of heart failure $(<1 \%)$ [31•]. Patients with T2D, similarly, had a very low incidence of heart failure $(<1 \%)$ [34]. Patients without diabetes but with insulin resistance and a previous ischemic cerebrovascular event had an increase in the incidence of heart failure and hospitalization for heart failure, but these were not related to pioglitazone treatment [65]. VA ambulatory patients with heart failure and diabetes had an increase in heart failure hospitalizations and death over a 2-year follow-up period and they were unrelated to TZD treatment $[72 \bullet \bullet]$. Three studies (PROactive, RECORD, and A GSK-sponsored ECHOCARDIOGRAPHIC study) showed significant increases in heart failure hospitalizations in patients treated with a TZD $[43 \bullet \bullet, 61,64 \bullet \cdot$. The populations in these three studies had in common a long duration of diabetes and a high prevalence of preceding cardiovascular events. While death from heart failure was increased by rosiglitazone in the RECORD study, death was not increased by pioglitazone in PROactive. It appears that TZDs increase edema and heart failure requiring additional treatment or hospitalization in patients with T2D with significant preceding cardiovascular disease. The available data indicate that pioglitazone treatment does not increase death from heart failure.

Rosiglitazone treatment of patients with T2D and NYHA functional class I or II heart failure for 52 weeks did not affect LVEF even though the patients experienced new or worsening edema and increased congestive heart failure medications [61].

\section{Thiazolidinediones and Bone Fractures}

The second major complication of TZD therapy is an increase in the risk of bone fractures. This was first reported in the results of the ADOPT study which was a long-term study to determine the durability of rosiglitazone as a treatment for glycemic control as compared with metformin or glyburide. In this study involving 2511 men and 1840 women, there was an increase in peripheral fractures in women but not men [36••]. After a median treatment of 4.0 years, 60 women $(9.3 \%$ or $2.74 / 100$ patient years) had at least one fracture. The cumulative incidence of fractures in women at 5 years of treatment was rosiglitazone $15.1 \%$, metformin $7.3 \%$, and glyburide $7.7 \%$. The HR for rosiglitazone-induced fractures was 1.81 and 2.11 relative to metformin or glyburide [36••]. The increase in fractures started after 1 year of treatment. A retrospective analysis of the data from the PROactive study found similar results with an increase in fracture risk in women $(5.1 \%$ vs. $2.5 \%$ or $1.0 \mathrm{vs.}$ $0.5 / 100$ person-years) but not in men ( 0.6 vs. $0.7 / 100$ personyears) compared with the control population [73].

Two other large randomized, controlled clinical trials reported an increase in fracture risk in TZD-treated patients with T2D. In the RECORD trial which randomized 4447 participants to rosiglitazone or combination metformin and sulfonylurea for a mean of 5.5 years, fracture risk for women was increased by rosiglitazone exposure (2.1/100 person-years compared with the active controls (1.1/100 person-years) but not in men $(1.0 / 100$ person-years vs. active controls $0.8 / 100$ person-years) [43*0]. In the IRIS trial of 3876 insulin-resistant subjects without diabetes, the 5 -year pioglitazone fracture risk was $13.6 \%$ compared with the placebo control of $8.8 \%$ with a HR of 1.53 [74•]. The fractures were due to a fall in $80 \%$, and $45 \%$ were serious and required hospitalization or surgery. The fracture risk from pioglitazone exposure was increased in both men $(9.4 \%$ vs. active control $5.2 \%, \mathrm{HR}=1.83)$ and women $(14.9 \%$ vs. active control $11.6 \%, \mathrm{HR}=1.32, p=0.13)$. The actual fracture rates were 2.3 vs. $1.3 / 100$ person-years for men and 3.7 vs. $2.8 / 100$ person-years for women. The rates in these IRIS participants were higher than in people with diabetes because of the high incidence of falls as these were subjects who had had a previous cerebral ischemic lesion [74•].

In the recently published data from the TOSCA-IT study comparing pioglitazone treatment to an active sulfonylurea therapy in 3028 participants with T2D patients for 57.3 months, there was no significant increases in fractures in pioglitazone exposed female or male participants [42].

Other data on TZD fracture risk come primarily from large medical databases or subanalyses from randomized controlled studies designed for other purposes. In the ACCORD study of intensive vs. ordinary glycemic control, $74 \%$ of participants received rosiglitazone and $17 \%$ received pioglitazone. During a mean follow-up of 4.8 years, 262 men and 287 women had at least one non-spinal fracture [75•]. There was no increase in 


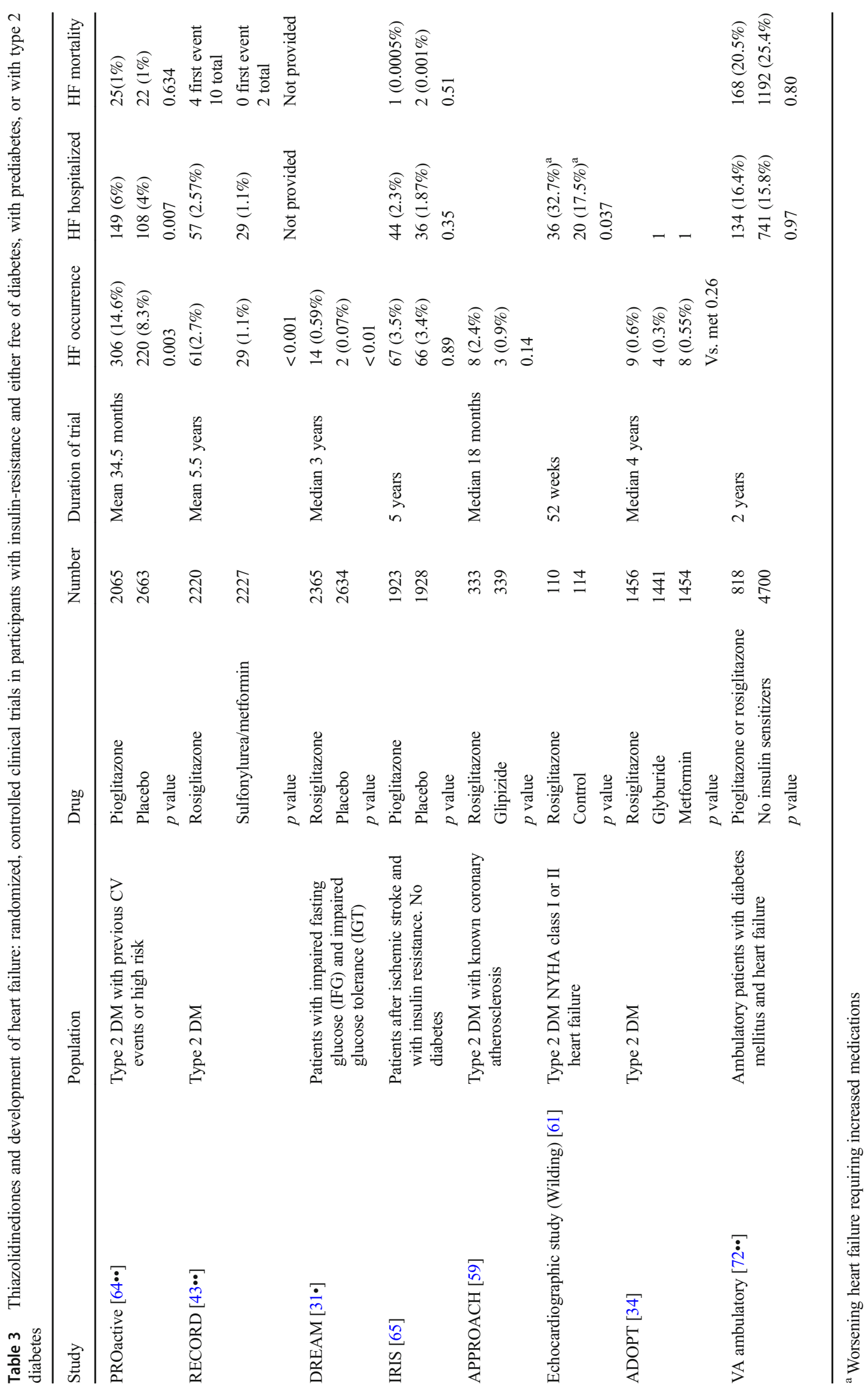


fracture risk in men receiving a TZD. Fracture rate in women with 1 to 2 years or $>2$ years TZD exposure had HR of 2.32 and 2.01, respectively. Discontinuing TZD use for 1 to 2 years or $>2$ years reduced the HR to 0.57 and 0.42 compared with current TZD users [75•].

Database studies confirm the increased risk of fractures in both pre- and postmenopausal TZD-exposed women. Fractures occur starting at 1 year of exposure are usually peripheral and are likely dose- and time-related. Though a few studies find some increase fracture risk in men exposed to TZDs, most do not.

\section{Pioglitazone and Bladder Cancer}

The specter that pioglitazone increases bladder cancer has been an issue for regulators and clinicians for more than a decade. A mismatch in the number of cases of bladder cancer was noted in the PROactive study (14 in the pioglitazone arm and 6 in the placebo arm) [40••]. An epidemiologic study of 1.5 million persons with diabetes followed for 4 years $(2002-$ 2006) by the French National Health Insurance Agency reported that pioglitazone-treated males had a statistically significant increase in bladder cancer $(\mathrm{HR}=1.22,95 \% \mathrm{CI}=$ 1.03-1.43) compared with patients treated with other antidiabetic agents [39]. The risk was increased with a total cumulative dose $>28,000 \mathrm{mg}(\mathrm{HR}=1.75)$ and for exposures $>1$ year $(H R=1.34)$. The French Agency for the Safety of Health Products withdrew pioglitazone from the French market on June 9, 2011, and Germany's Federal Institute for Drugs and Medical Devices on June 10, 2011, advised physicians not to prescribe pioglitazone until the issue of pioglitazone and bladder cancer was resolved.

A 10-year follow-up study of pioglitazone use and bladder cancer was agreed upon by the Kaiser Permanente Group of California and the US FDA. The study involved 193,099 persons aged 40 years and older in 1997-2002 who were diagnosed with diabetes and managed by the Kaiser health care system and were followed until December 2012 [76••]. Of the cohort, 34,181 (18\%) received pioglitazone (mean 2.8 (0.2 to 13.2) years) and 1261 had incident bladder cancer. Ever use of pioglitazone was not associated with the development of bladder cancer $(\mathrm{HR}=1.06 ; 95 \% \mathrm{CI}=0.89-1.26)$. In a comparison of 464 bladder cancer patients with 464 matched controls, the adjusted OR for pioglitazone use vs. no use was 1.18 (95\% CI = $0.78-1.80)$ [76••]. Several additional studies support the findings that pioglitazone does not increase bladder cancer [77-79].

\section{Comparison of Pioglitazone to Rosiglitazone}

There have been no randomized, controlled clinical trials comparing the efficacy and safety of rosiglitazone and pioglitazone. The TIDE study which was designed to obtain this information was discontinued after 162 days because of the FDA's concern about the cardiovascular safety of rosiglitazone and the ensuing public apprehension which would have made recruitment difficult and biased [56]. The only comparative data available are database analyses and meta-analyses.

There are basic studies which do raise the possibility that there may be some differences in the clinical effects of rosiglitazone and pioglitazone. PPARs represent a complicated family of nuclear receptors: $\operatorname{PPAR} \alpha, \operatorname{PPAR} \beta \delta$, and PPAR $\gamma$ $[80,81]$. PPAR $\alpha$ primarily facilitates fatty acid oxidation and lipid utilization, while PPAR $\gamma$ promotes differentiation of stem cells into adipocytes and facilitates peripheral adipose tissue cells to store rather than release fatty acids. Furthermore, there are three distinct isoforms of PPAR $\gamma: \operatorname{PPAR} \gamma 1$ (expressed in almost all tissues), PPAR $\gamma 2$ (expressed mainly in adipose tissue), and PPAR $\gamma 3$ (expressed in macrophages, colon and white adipose tissue). Pioglitazone is a selective human PPAR $\gamma 1$ and a weak human PPAR $\alpha$ activator [82]. Chemical proteomics-based analysis profiles show that while there are many common products for pioglitazone and rosiglitazone; there are also many unique products for each [83]. One proven difference between the two TZDs is their effect on human lipid profiles. Rosiglitazone has a less beneficial effect on plasma lipids than pioglitazone: greater increase in VLDL particles; increased LDL particle concentration vs. decrease in LDL particle concentration with pioglitazone; decreased HDL particle concentration and size while pioglitazone increased them [84].

Therefore, it would not be surprising to see differences in the clinical effects of these two TZDs. Unfortunately, as noted above, there are no randomized controlled trials comparing the two. There are database analyses and meta-analyses that conclude that pioglitazone has a greater benefit on cardiovascular outcomes and a lesser side effect profile than rosiglitazone. All these analyses are questionable because they are influenced by selection bias, and the studies that were carried out with rosiglitazone as compared with pioglitazone were suboptimal. For example, PROactive provided much more meaningful data than RECORD. The controversy surrounding rosiglitazone starting in 2007 would be expected to have influenced patient antidiabetic treatment selection and maintenance of treatment in all database analyses. Major unknowns with relevance to side effects and efficacy include the adjustments made in TZD doses and the effects of other drugs, such as diuretics, used to treat fluid retention and heart failure. The development of edema and heart failure appears to be influenced by the underlying degree of vascular disease. In Tables 2 and 3, patients with insulin resistance and prediabetes had very low incidence of edema and heart failure followed by the highest incidence in those who had very significant cardiovascular disease at entry into studies. 


\section{Conclusions}

The TZD class of drugs uniquely treats insulin resistance which is the major cause of the increase in T2D and a large component of the increase in atherosclerotic cardiovascular disease. The positive benefits accrued from TZD treatment are summarized in Table 1 . The use of these previously extensively prescribed and effective treatments for T2D has been remarkably diminished because of concerns about safety and side effects such as heart failure and increased risk of fractures. Data have been presented to dispel the safety concerns and put the complications into a rational perspective. These drugs are generic, cost is not overly excessive, and they are the most effective pharmacologic agents for treating insulin resistance.

\section{Compliance with Ethical Standards}

Conflict of Interest Harold E. Lebovitz declares that he has no conflict of interest.

Human and Animal Rights and Informed Consent This article does not contain any new studies with human or animal subjects performed by any of the authors. All of the data quoted in this review have been published in peer-reviewed journals and would have complied with the standards of informed consent.

Open Access This article is distributed under the terms of the Creative Commons Attribution 4.0 International License (http:// creativecommons.org/licenses/by/4.0/), which permits unrestricted use, distribution, and reproduction in any medium, provided you give appropriate credit to the original author(s) and the source, provide a link to the Creative Commons license, and indicate if changes were made.

\section{References}

Papers of particular interest, published recently, have been highlighted as:

- Of importance

•. Of major importance

1. Weyer C, Bogardus C, Mott DM, Pratley RE. The natural history of insulin secretory dysfunction and insulin resistance in the pathogenesis of type 2 diabetes mellitus. 1999;104:787-94. This is the classic study that documents the relationship between insulin resistance and insulin secretion.

2.• Savage DB, Petersen KF, Shulman GI. Disordered Lipid metabolism and the pathogenesis of insulin resistance. Physiol Rev. 2007;87:507-20. This review outlines how ectopic fat leads to insulin resistance.

3.• Lebovitz HE, Banerji MA. Treatment of insulin resistance in diabetes mellitus. Eur J Pharmacol. 2004;490:135-46. This summarizes the beneficial effects of TZDs on the insulin resistance syndrome.

4. Czech MP. Insulin action and resistance in obesity and type 2 diabetes. Nat Med. 2017;7:804-14.
5. Lebovitz HE. In: Wass JAH, Stewart PM, editors. The metabolic syndrome chapter 13.36 in Oxford textbook of endocrinology and diabetes $2^{\text {nd }}$ Edition. Oxford: OXFORD University Press; 2011.

6. Reaven GM. Banting lecture 1988: role of insulin resistance in human disease. Diabetes. 1988;37:1595-607. This summarizes the pioneer studies which formulated the concept of insulin resistance as a cause of atherosclerotic disease.

7. Meigs JB, Wilson PW, Fox CS, Vasan RS, Nathan DM, Sullivan LM, et al. Body mass index, metabolic syndrome and risk of type 2 diabetes or cardiovascular disease. J Clin Endocrinol Metab. 2006;91:2906-12.

8. Ford ES. Risks for all-cause mortality, cardiovascular disease and diabetes associated with the metabolic syndrome. Diabetes Care. 2005;28:1769-78.

9. Banerji MA, Lebovitz HE. Insulin-sensitive and insulin-resistant variants in NIDDM. Diabetes. 1989;38:784-92.

10.• Alexander CM, Landsman PB, Teutsch SM, Haffner SM. NCEPdefined metabolic syndrome, diabetes, and prevalence of coronary heart disease among NHANES III participants age 50 years and older. Diabetes. 2003;52:1210-4. This study helps to define diabetes mellitus and the metabolic syndrome as separate but interacting metabolic abnormalities.

11. Origin Trial Investigators. Basal insulin and cardiovascular and other outcomes in dysglycemia. N Engl J Med. 2012;367:319-28.

12. Nauck MA, Meier JJ, Cavender MA, El Aziz MA, Drucker DJ. Cardiovascular actions and clinical outcomes with glucagon-like peptide-1 receptor agonists and dipeptidyl peptidase- 4 inhibitors. Circulation. 2017;136:849-70.

13. Htike ZZ, Zaccardi E, Papamargaritis D, Webb DR, Khunti K, Davies MJ. Efficacy and safety of glucagon-like peptide-1 receptor agonist in type 2 diabetes: a systematic review and mixed-treatment comparison analysis. Diabetes Obes Metab. 2017;19:524-36.

14. ChenX-W HZ-X, Zhou Z-W, et al. Clinical pharmacology of dipeptidyl peptidase 4 inhibitors indicated for treatment of type 2 diabetes mellitus. Clin Exp Pharmacol Physiol. 2015;42:999-1024.

15. Merovci A, Solis-Herrera C, Daniele G, Eldor R, Florentino TV, Tripathy D, et al. Dapagliflozin improves muscle insulin sensitivity but enhances endogenous glucose production. J Clin Invest. 2014;124:509-14.

16. Ferrannini E, Muscelli E, Frascerra S, Baldi S, Mari A, Heise T, et al. Metabolic response to sodium-glucose cotransporter 2 inhibition in type 2 diabetic patients. J Clin Invest. 2014;124:499-508.

17. Lim EL, Hollingsworth KG, Aribisala BS, Chen MJ, Mathers JC, Taylor R. Reversal of type 2 diabetes: normalization of beta cell function in association with decreased pancreas and liver triacylglycerol. Diabetologia. 2011;54:2506-14. One of the best demonstrations of the effect of weight loss on metabolic processes.

18.• Lebovitz HE, Banerji MA. Insulin resistance and its treatment by thiazolidinediones. Recent Prog Horm Res. 2001;56:265-94. A summary of the beneficial effects of TZDs on the components of the insulin resistance syndrome.

19. Tontonoz P, Spiegelman BM. Fat and beyond: the diverse biology of PPAR $\gamma$. Annu Rev Biochem. 2008;77:289-312.

20. Olefsky JM, Saltiel AR. PPAR $\gamma$ and the treatment of insulin resistance. Trends in Endocrinol and Metab. 2000;11:362-8.

21. Stumvoll M, Nurjahan N, Perriello G, Dailey G, Gerich JE. Metabolic effects of metformin in non-insulin-dependent diabetes mellitus. N Engl J Med. 1995;333:550-4.

22. Pernicova I, Korbonits M. Metformin - mode of action and clinical implications for diabetes and cancer. Nat Rev Endocrinol. 2014;10: 143-56.

23. Prentki $\mathrm{M}$, Nolan CJ. Islet $\beta$-cell failure in type 2 diabetes. J Clin Invest. 2006;116:1802-12.

24.• Shulman GI. Ectopic fat in insulin resistance, dyslipidemia, and cardiometabolic disease. N Engl J Med. 2014;371:1131-41. An excellent overview of the relationship between ectopic fat and 
its mechanism in creating insulin resistance and cardiovascular disease.

25. Olefsky JM, Glass CK. Macrophages, inflammation, and insulin resistance. Annu Rev Physiol. 2010;72:219-46.

26. Zeyda M, Stulnig TM. Obesity, inflammation, and insulin resistance - a mini-review. Gerontology. 2009;55:379-86.

27. Kaur R, Kaur M, Singh J. Endothelial dysfunction and platelet hyperactivity in type 2 diabetes mellitus: molecular insights and therapeutic strategies. Cardiovasc Diabetol. 2018;17:121.

28. Kasuga M. Insulin resistance and $\beta$ cell failure. J Clin Invest. 2006;116:1756-60.

29. Taylor R, Barnes AC. Translating aetiological insight into sustainable management of type 2 diabetes. Diabetologia. 2018;61:27383.

30. Staels B, Fruchart J-C. Therapeutic roles of peroxisome proliferator-activated receptor agonists. Diabetes. 2005;54:2460 70.

31. The DREAM Trial Investigators. Effect of rosiglitazone on the frequency of diabetes in patients with impaired glucose tolerance or impaired fasting glucose: a randomized controlled trial. Lancet. 2006;368:1096-105. TZDs decrease insulin resistance and preserve beta-cell function.

32. DeFronzo RA, Tripathy D, Schwenke DC, Banerji MA, Bray GA, Buchanan TA, et al. Pioglitazone for diabetes prevention in impaired glucose tolerance. N Engl J Med. 2011;364:1104-15.

33. Gervois P, Fruchard J-C, Staels B. Drug insight: mechanisms of action and therapeutic applications for agonist of peroxisome proliferator-activated receptors. Nat Clin Pract Endocrinol and metab. 2007:3:145-56.

34. Kahn SE, Haffner SM, Heise MA, Herman WH, Holman RR, Jones NP, et al. Glycemic durability of rosiglitazone, metformin, or glyburide monotherapy. N Engl J Med. 2006;355:2427-43.

35. Nesto RW, Bell D, Bonow RO, Fonseca V, Grundy SM, Horton ES, et al. Thiazolidinedione use, fluid retention, and congestive heart failure. A Consensus Statement from the American Heart Association and American Diabetes Association. Circulation. 2003;108:2941-8. Focused attention on TZD effects in increasing fluid retention and precipitating heart failure.

36.• Kahn SE, Zinman B, Lachin JM, Haffner SM, Herman WH, Holman RR, et al. Rosiglitazone-associated fractures in type 2 diabetes. An Analysis from a Diabetes Outcome Progression Trial (ADOPT). Diabetes Care. 2008;31:845-51. First recognition that TZDs cause an increased risk of peripheral skeletal fractures.

37. Nissen SE, Wolski K. Effect of rosiglitazone on the risk of myocardial infarction and death from cardiovascular causes. N Engl J Med. 2007;356:2457-71.

38. Singh S, Loke YK, Furberg CD. Long-term risk of cardiovascular events with rosiglitazone. A Meta-analysis JAMA. 2007;298:118995 .

39. Neumann A, Weill A, Ricordeau P, Fagot JP, Alla F, Allemand H. Pioglitazone and risk of bladder cancer among diabetic patients in France: a population-based cohort study. Diabetologia. 2012;55: 1953-62.

40.• Dormandy JA, Charbonnel B, DJA E, Erdmann E, Massi-Benedetti $\mathrm{M}$, Moules IK, et al. Secondary prevention on macrovascular events in patients with type 2 diabetes in the PROactive Study (PROspective pioglitAzone Clinical Trial In macroVascular Events): a randomized, controlled trial. Lancet. 2005;366:127989. Initial cardiovascular safety trial for a single antidiabetic drug. Data suggest a possible benefit of TZDs in reducing cardiovascular events in patients with type 2 diabetes.

41.• Kernan WN, Viscoli CM, Furie KL, Young LH, Inzucchi SE, Gorman M, et al. Pioglitazone after ischemic stroke or transient ischemic attack. New Engl J Med. 2016;374:1321-31. This study proves the beneficial effects of pioglitazone in reducing $\mathrm{CV}$ events in patients with type 2 diabetes.
42. Vaccaro O, Masulli M, Nicolucci A, Bonora E, Del Prato S, Maggoini AP, et al. Effects of the incidence of cardiovascular events of the addition of pioglitazone versus sulfonylureas in patients with type 2 diabetes inadequately controlled with metformin (TOSCA.IT): a randomized, multicenter trial. Lancet Diabetes Endocrinol. 2017;5:887-97.

43.• Home RD, Pocock S, Beck-Nielsen H, Curtis PS, Gomis R, Hanefeld M, et al. Rosiglitazone evaluated for cardiovascular outcomes in oral agent combination therapy for type 2 diabetes (RECORD): a multicenter, randomized, open label trial. Lancet. 2009;373:2125-35. A mediocre CV safety study with rosiglitazone. It did however dispel the claims that rosiglitazone caused an increase in $\mathrm{CV}$ events and death in patients with type 2 diabetes.

44. Wilcox R, Bousser M_G, Betteridge J, Schernthaner G, Pirags V, Kupfer S, et al. Effects of pioglitazone in patients with type 2 diabetes with or without previous stroke. Results from PROactive (PROspective pioglitAzone Clinical Trial In macroVascular Events 04). Stroke. 2007;38:865-73.

45. Kernan WN, Viscoli CM, Dearborn JL, Kent DM, Conwit CR, Fayad P, et al. Targeting pioglitazone hydrochloride therapy after stroke or transient ischemic attack according to pretreatment risk for stroke or myocardial infarction. JAMA Neurol. 2017;74:1319-27.

46. Lee M, Saver JL, Liao H-W, Lin C-H, Ovbiagele B. Pioglitazone for secondary stroke prevention: a systemic review and meta-analysis. Stroke. 2017;48:388-93.

47. Nissen SE, Nicholls SJ, Wolski K, Nesto R, Kupfer S, Perez A, et al. Comparison of pioglitazone vs glomepiride on progression of coronary atherosclerosis in patients with type 2 diabetes. JAMA. 2008;299:1561-73.

48. Nathan DM, Buse JB, Dasvidson MB, Ferrannini E, Holman RR, Sherwin R, et al. Management of hyperglycemia in type 2 diabetes: a consensus algorithm for the initiation and adjustment of therapy. Update regarding thiazolidinediones: a consensus statement from the American diabetes Association and the European Association for the Study of Diabetes. Diabetes Care. 2008;31:173-5.

49. Kaul S, Bolger AF, Herrington D, Giugliano RP, Eckel RH. Thiazolidinedione drugs and cardiovascular risks. J Amer Coll Cardiol. 2010;55:1885-94.

50. Juurlink DN. Rosiglitazone and the case for safety over certainty. JAMA. 2010;304:469-71.

51. Rosen CJ. Revisiting the rosiglitazone story-lessons learned. N Engl J Med. 2010;363:803-6. Reviews the FDA deliberations which lead to the FDA restricting the use of rosiglitazone.

52. Bourg CA, Phillips BB. Rosiglitazone, myocardial ischemic risk and recent regulatory actions. Ann Pharmacother. 2012;46:282-9.

53. Graham DJ, Ouellet-Hellstrom R, MaCurdy TE, Ali F, Sholley C, Worrall C, et al. Risk of acute myocardial infarction, stroke, heart failure, and death in elderly Medicare patients treated with rosiglitazone or pioglitazone. JAMA. 2010;304:411-8.

54. Mitka M. Panel recommends easing restrictions on rosiglitazone despite concerns about cardiovascular safety. JAMA. 2013;310: 246-7.

55. FDA Drug Safety Communication. FDA requires removal of some prescribing and dispensing restrictions for rosiglitazone-containing diabetes medicines. Nov. 2013;25.

56. The Tide Trial Investigators. Design, history and results of the Thiazolidinedione Intervention with vitamin D Evaluation (TIDE) randomized controlled trial. Diabetologia. 2012;55:36-45.

57. Bach RG, Brooks MM, Lombardero M, Genuth S, Donner TW, Garber A, et al. Rosiglitazone and outcomes for patients with diabetes mellitus and coronary heart disease in the Bypass Angioplasty Revascularization Investigation 2 Diabetes (BARI 2D) trial. Circulation. 2013;128:785-94. 
58. Florez H, Reaven PD, Bahn G, Moritz T, Warren S, Marks J, et al. Rosiglitazone treatment and cardiovascular disease in Veterans Affairs Diabetes Trial. Diabetes Obes Metab. 2015;17:949-55.

59. Gerstein HC, Ratner RE, Cannon CP, Serruys PW, Garcia-Garcia $\mathrm{HM}$, van Eas G-A, et al. Effect of rosiglitazone on progression of coronary atherosclerosis in patients with type 2 diabetes mellitus and coronary artery disease. The assessment on the prevention of progression by rosiglitazone on atherosclerosis in diabetes with cardiovascular history trial. Circulation. 2010;121:1176-87.

60. Choi D, Kim S-K, Choi S-H, Ko Y-G, Ahn C-W, Jang Y, et al. Preventative effects of rosiglitazone on restenosis after coronary stent implantation in patients with type 2 diabetes. Diabetes Care. 2004;27:2654-60.

61. Dargie HJ, Hildebrandt PR, Piegger GAJ, McMurray JJV, McMorn $\mathrm{SO}$, Roberts JN, et al. A randomized, placebo-controlled trial assessing the effects of rosiglitazone on echocardiographic function and cardiac status in type 2 patients with New York heart association functional class I or II heart failure. J Am Coll Cardiol. 2007;49:1696-704.

62. Fu Y, Gerasimova M, Batz F, Kuczkowski A, Alam Y, Sanders PW, et al. PPAR $\gamma$ agonist-induced fluid retention depends on $\alpha \mathrm{ENaC}$ expression in connecting tubules. Nephron. 2015;129:68-74.

63. Horita S, Nakamura M, Satoh N, Suzuki M, Seki G. Thiazolidinediones and edema: recent advances in the pathogenesis of thiazolidinediones-induced renal sodium retention. PPAR Research. 2015. https://doi.org/10.1155/2015/646423.

64.• Erdmann E, Charbonnel B, Wilcox RG, Skene AM, MassiBenedetti M, Yates J, et al. Pioglitazone use and heart failure in patients with type 2 diabetes and preexisting cardiovascular disease. Data from the PROactive Study (PROactive 08). Diabetes Care. 2007;30:2773-8. Detailed analysis fluid retention and heart failure development and outcome with pioglitazone treatment.

65. Young LH, Viscoli CM, Schwartz GG, Inzucchi SE, Curtis JP, Gorman MJ, et al. Heart failure after ischemic stroke or transient ischemic attack in insulin-resistant patients without diabetes mellitus treated with pioglitazone. Circulation. 2018;138:1210-20.

66. Berthet S, Oliver P, Montastruc J-L, Lapeyre-Mestre M. Drug safety of rosiglitazone and pioglitazone in France: a study using the French PharmacoVigilance database. BMC Clin Pharmacol. 2011;11:5. This study lead to the restriction of pioglitazone use in France and Germany.

67. Goltsman I, Khoury EE, Winaver J, Abassi Z. Does thiazolidinedione therapy exacerbate fluid retention in congestive heart failure? Pharmacol Ther. 2016:75-97.

68. Wooltorton E. Rosiglitazone (Avandia) and pioglitazone (Actos) and heart failure. CMAJ. 2002;22:166.

69. Delea TE, Edelsberg JS, Hagiwara M, Oster G, Phillips LS. Use of thiazolidinediones and risk of heart failure in people with type 2 diabetes: a retrospective cohort study. Diabetes Care. 2003;26: 2983-9.

70. Leier CV, Haas GJ. Diabetes and heart failure. J Ame Coll Cardiol. 2007; 50:

71. Lago RM, Singh PP, Nesto RW. Congestive heart failure and cardiovascular death in patients with prediabetes and type 2 diabetes given thiazolidinediones: a meta-analysis of randomized clinical trials. Lancet. 2007;370:1129-36.

72.• Aguilar D, Bozkurt B, Pritchett A, Petersen NJ, Deswal A. The impact of thiazolidinedione use on outcomes in ambulatory patients with diabetes mellitus and heart failure. $\mathrm{J}$ Amer Coll Cardiol. 2007;50:32-6. Best data on the effect of TZD treatment in patients with heart failure.

73. Dormandy J, Bhattacharya M, van Troostenburg de Bruyn AR, PROactive investigators. Safety and tolerability of pioglitazone in high risk patients with type 2 diabetes: an overview of data from PROactive. Drug Saf. 2009;32:187-202.

74. Viscoli CM, Inzucchi SE, Young LH, Insogna KL, Conwit R, Furie KL, et al. Pioglitazone and risk for bone fracture: safety data from a randomized clinical trial. J Clin Endocrinol Metab. 2017;102:914 22. Adds additional information about TZD effects on bone fracture. Significant relationship to falls and does occur in high-risk men.

75. Schwartz AV, Chen H, Ambrosius WT, Soad A, Josse RG, Bonds $\mathrm{DE}$, et al. Effects of TZD use and discontinuation on fracture rates in ACCORD bone study. J Clin Endocrinol Metab. 2015;100: 4059-66. An excellent analysis of TZD fracture risk in women and its requirement for continuing exposure.

76.• Lewis JD, Habel LA, Quesenberry CP, Strom BL, Peng T, Hedderson MM, et al. Pioglitazone use and risk of bladder cancer and other common cancers in persons with diabetes. JAMA. 2015;314:265-77. The data indicate that pioglitazone does not increase bladder cancer in men.

77. Davidson MB. Pioglitazone (Actos) and bladder cancer: legal system triumphs over the evidence. J Diabetes Complicat. 2016;30: 981-5.

78. Filipova E, Uzunova K, Kalinov K, Vekov T. Pioglitazone and the risk of bladder cancer: a meta-analysis. Diabetes Ther. 2017;8:706 26.

79. Tuccori M, Filion KB, Yin H, Yu OH, Platt RW, Azoulay L. Pioglitazone use and risk of bladder cancer: population-based cohort study. BMJ. 2016;352:i5141.

80. Willison TM, Cobb JE, Cowan DJ, Wiethe RW, Correa ID, Prakash $\mathrm{SR}$, et al. The structure-activity relationship between peroxisome proliferator-activated receptor $\gamma$ agonism and the antihyperglycemic activity of thiazolidinediones. J Med Chem. 1996;39:665-8.

81. Gervois P, Fruchart J-C, Staels B. Drug insight: mechanisms of action and therapeutic applications for agonists of peroxisome proliferator-activated receptors. Nat Clin Pract Endocrinol Metab. 2007;3:145-55.

82. Sakamoto J, Kimura H, Moriyama S, Odaka H, Momose Y, Sugiyama Y, et al. Activation of human peroxisome proliferatoractivated receptor (PPAR) subtypes by pioglitazone. Biochem Biophy Res Commun. 2000;278:704-11.

83. Hoffmann BR, El-Mansy MF, Sem DS, Greene AS. Chemical proteomics-based analysis of off-target binding profiles for rosiglitazone and pioglitazone: clues for assessing potential for cardiotoxicity. J Med Chem. 2012;55:8260-71.

84. Ma D, Buse JB, Goldberg RB, Kendall DM, Zagar AJ, Jacober SJ, et al. Pioglitazone and rosiglitazone have different effects on serum lipoprotein particle concentrations and sizes in patients with type 2 diabetes and dyslipidemia. Diabetes Care. 2007;30(10):2458-64 Epub 2007 Jun 26.

Publisher's Note Springer Nature remains neutral with regard to jurisdictional claims in published maps and institutional affiliations. 